\title{
A Nuclear Future? UK Government Policy and the Role of the Market?
}

David Newbery

March 2010

CWPE 1019 \& EPRG 1011 


\title{
A Nuclear Future? UK Government policy and the role of the market ${ }^{1}$
}

\author{
David Newbery ${ }^{2}$ \\ University of Cambridge \\ 15 December 2009 \\ revised 25 March 2010
}

UK energy policy has evolved since the 2002 Energy Review (PIU, 2002) in which Tony Blair introduced the report and noted that "securing cheap, reliable, and sustainable sources of energy has long been a major concern for governments”. The new Department of Energy and Climate Change, DECC, has rephrased its objectives ${ }^{3}$ to "ensure our energy is secure, affordable and efficient” and "bring about a transition to a low-carbon Britain”. The shift from "cheap" to "affordable" is significant, as meeting the low-carbon (low-C) targets will not be cheap, but should be affordable. We forget that in the interwar period electricity prices were three to four times more expensive than now in real terms. Since then dramatic improvements in efficiency have allowed costs and prices to fall. If one considers that real wages have improved by a factor of four over this period, electricity prices relative to earning power are now less than one tenth of their interwar level.

The target of reducing Greenhouse Gas (GHG) to 80\% below 1990 levels by 2050 is best achieved by decarbonising electricity, as that is much easier than decarbonising any other fuel. At present we consume roughly one third of daily energy needs in transport, onethird in heating and one third in the primary energy used to produce electricity. Heating can be replaced more efficiently through electric powered heat pumps, road transport might be replaced by electric vehicles, resulting in an almost entirely carbon free economy (Mackay 2009).

Zero-carbon electricity can be generated from a variety of sources, many of which are only available in limited local supply and cost substantially more than current fossil fuels. If fossil generation paid the full social cost of carbon, nuclear power and much on-shore wind power would already be competitive in favoured locations, but carbon capture and storage (CCS) and many renewables (biomass, tidal stream, wave power, photovoltaic or PV, and even concentrated solar thermal power) would still not be commercially competitive, particularly at commercial interest rates.

The case for renewable electricity supply (RES) is that it may be more suitable for many developing countries than other low-C options, particularly nuclear power with its proliferation risks, high skill requirements and minimum economic scale. If RES is to be more widely deployed their costs must be driven down through research, development, and

\footnotetext{
${ }^{1}$ Paper presented to the Beesley Lectures on Regulation in London on 22 October 2009.

${ }^{2}$ Research Director, Electricity Policy Research Group, corresponding address Faculty of Economics, Sidgwick Avenue, Cambridge, England CB3 9DE, email dmgn@econ.cam.ac.uk. Research support by the ESRC to the Electricity Policy Research Group, EPRG, under the programme Towards a Sustainable Energy Economy is gratefully acknowledged. I am indebted to helpful comments from Chris Hall and Lewis Dale and to an anonymous referee for the EPRG working paper series.

${ }^{3}$ http://www.decc.gov.uk/en/content/cms/about/about.aspx accessed 8 Dec 2009
} 
deployment (RD\&D, including learning-by-doing). Supporting RES is therefore justified not by the carbon saved (which should be addressed through carbon pricing) but through the induced innovation and learning-by-doing that deployment might deliver. The case for EUwide RES targets is simply as an equitable burden-sharing arrangement to provide the public good of this RD\&D.

The Committee on Climate Change (CCC) reported in 2008, also arguing that decarbonising electricity was the key to meeting the 2030 carbon targets, which require electricity to have an average $\mathrm{CO}_{2}$ (carbon-dioxide) intensity of about $70 \mathrm{~g} / \mathrm{kWh}$ compared to the present figure of over $550 \mathrm{~g} / \mathrm{kWh}$. Given the durability of power plant, that implies that essentially everything now built must be zero or very low-C generation. CCC (2008) argued that nuclear power was cost-competitive and the economic case was strong given a significant carbon price and future expected high fuel prices, although delivery would be constrained on the supply side (because of possible shortages of finance, engineers, and companies with access the relevant technologies). Their forecast was for a central case $\mathrm{CO}_{2}$ price of $€ 50 / E U A$ in $2020,{ }^{4}$ based on the assumption that the carbon price would be set by the trade-off between coal and gas-fired generation.

\section{EUA price 25 October 2004-27 September 2009}

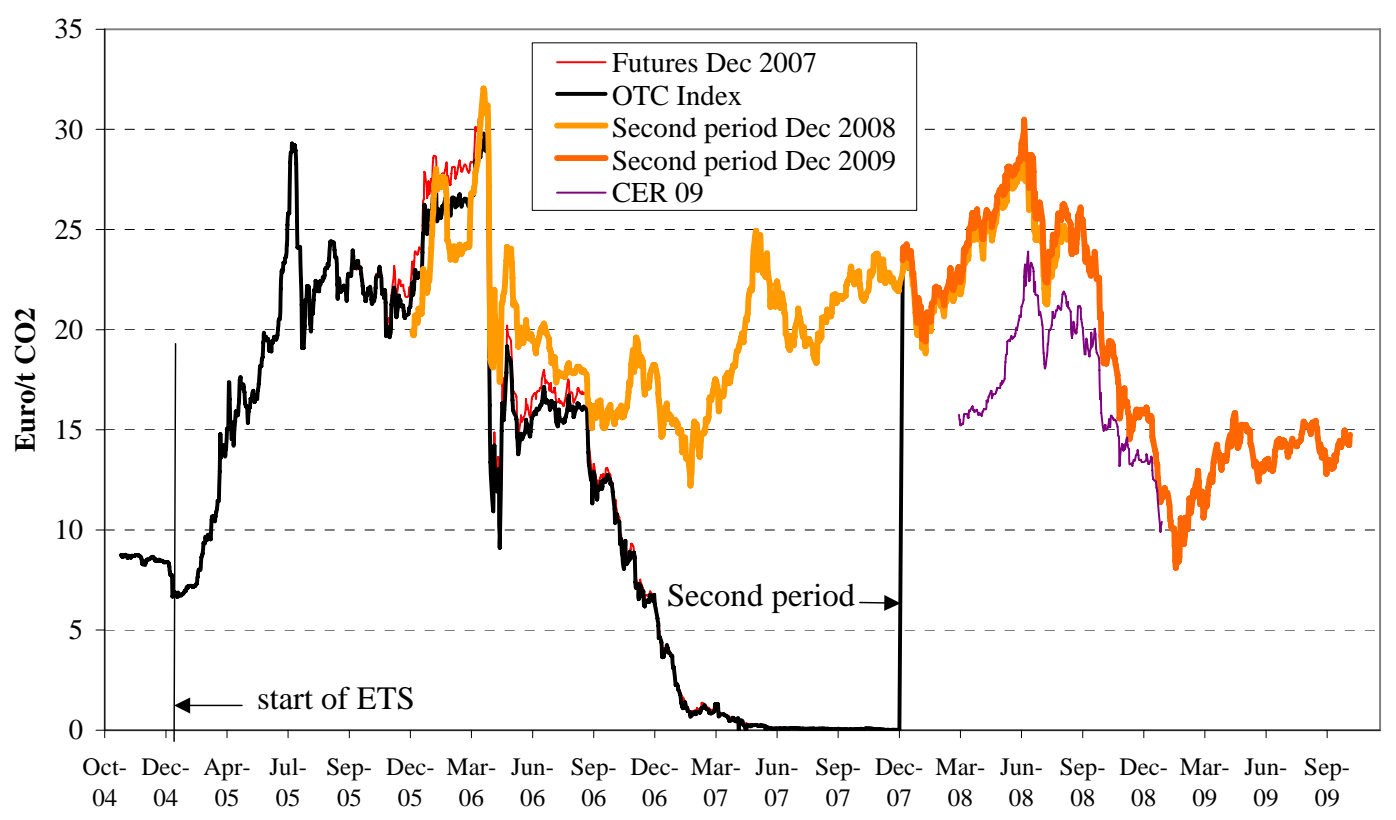

\section{Figure 1 The EU price of $\mathrm{CO}_{2}$}

Figure 1 shows that although the EUA price reached over $€ 30 / E U A$ in June 2008, it then fell to less than half that level during 2009, and CCC (2009) now forecasts €20/EUA for 2020, which is too low for commercial investment in low-C generation. The implication is that policy intervention is required to raise the forecast minimum price of $\mathrm{CO}_{2}$, either through tightening the ETS cap or through other support mechanisms such as contracts for differences

\footnotetext{
${ }^{4}$ The EUA is the EU allowance price for 1 tonne of $\mathrm{CO}_{2}$ set by the EU Emissions Trading System (ETS).
} 
or a supplementary carbon tax. The former would be fiscally costly, while the latter could be fiscally positive but might be consider illegal by the CEC as discriminatory without a suitable (and desirable) EU-wide agreement. There are precedents for an EU-wide agreement on taxes - for example the minimum levels for various oil products - and in any case member states are free to set excise taxes as they choose, although without EU-wide harmonisation there would be problems of leakage. The production of carbon-intensive products might migrate to the lowest carbon cost country, although it might be possible to exempt export-exposed products or industries from the supplementary carbon tax. ${ }^{5}$

In Britain one possible approach would be to reform the Climate Change Levy (CCL) into a Carbon Correction Levy (also CCL) that would be extended to the whole economy and levied on the carbon content of fuel. It could start at the current CCL level and escalate annually so that by the commissioning date of large new zero-carbon generation it had reached an acceptable level. Industries in the sector covered by the EU ETS would then claim back the value of the EUAs submitted, ensuring that everyone in the economy faced the same effective carbon price. It would admittedly be challenging to find a way of rebating or protecting the trade-exposed sectors, although the Scandinavian countries managed this with varying success when they imposed carbon taxes, and in the UK diesel fuel used in agricultural machinery and fishing boats is exempt from the normal excise tax.

CCC (2009) noted that emissions had fallen over the period 2003-7 by less than $1 \%$ p.a. and needed to fall by between $2 \%$ and $3 \%$ p.a., depending on the targets agreed at Copenhagen. The recession was masking the poor performance of cutting emissions and also undermining the EU emissions trading system (ETS). The CCC report also noted the need to review electricity market arrangements and the mechanism for supporting renewables, which amplifies risk, increasing the cost of support and reduces incentives for speedy deployment. The recent gyrations in the EUA market underline the uncertainty about the future $\mathrm{CO}_{2}$ price. The earlier target of $\mathrm{CO}_{2}$ intensity in electricity for a fully efficient market has now risen to about $120 \mathrm{~g} \mathrm{CO}_{2} / \mathrm{kWh}$ in 2030 , but the report notes that in a world of uncertainty and myopia the intensity may exceed $200 \mathrm{~g} \mathrm{CO}_{2} / \mathrm{kWh}$, undermining the route to a low-C market. Figure 2 puts these figures into perspective, and shows that France reduced emissions from over $500 \mathrm{~g}$ $\mathrm{CO}_{2} / \mathrm{kWh}$ in 1974 to $100 \mathrm{~g} \mathrm{CO}_{2} / \mathrm{kWh}$ by 1987 . In contrast the current UK level is $540 \mathrm{~g}$ $\mathrm{CO}_{2} / \mathrm{kWh}$ and the target for 2020 is now only $300 \mathrm{~g} \mathrm{CO}_{2} / \mathrm{kWh}$ (CCC, 2009).

Mackay (2009) argues that any plan to decarbonise the economy must “add up” and identify the sources of electricity supply to meet the 2050 target of $70 \mathrm{kWh} /$ day/person. Of the five plans that he illustrates, three of them propose a relatively modest role for nuclear power and instead propose considerable quantities of solar power delivered from North African deserts. The " economic” plan E suggests that 44 out of the $70 \mathrm{kWh}$ should come from nuclear power. The other plan D “diversity” suggests $16 \mathrm{kWh}$ from nuclear, and a similar amount from clean coal with wind supplying $8 \mathrm{kWh}$ and the remainder from a variety of sources. (In all these scenarios heat pumps supply $12 \mathrm{kWh}$ "free" as a contribution to the $70 \mathrm{kWh}$, being the surplus from displacing inefficient heat raising sources - an efficient heat

\footnotetext{
5 The French government had hoped to introduce a carbon tax in July 2010, but it was apparently opposed by the Constitutional Court because too many categories of taxpayers were exempted.
} 
pump can produce four times the amount of heating than the energy content of the electricity used to power it.)

\section{CO2 emissions per kWh 1971-2000}

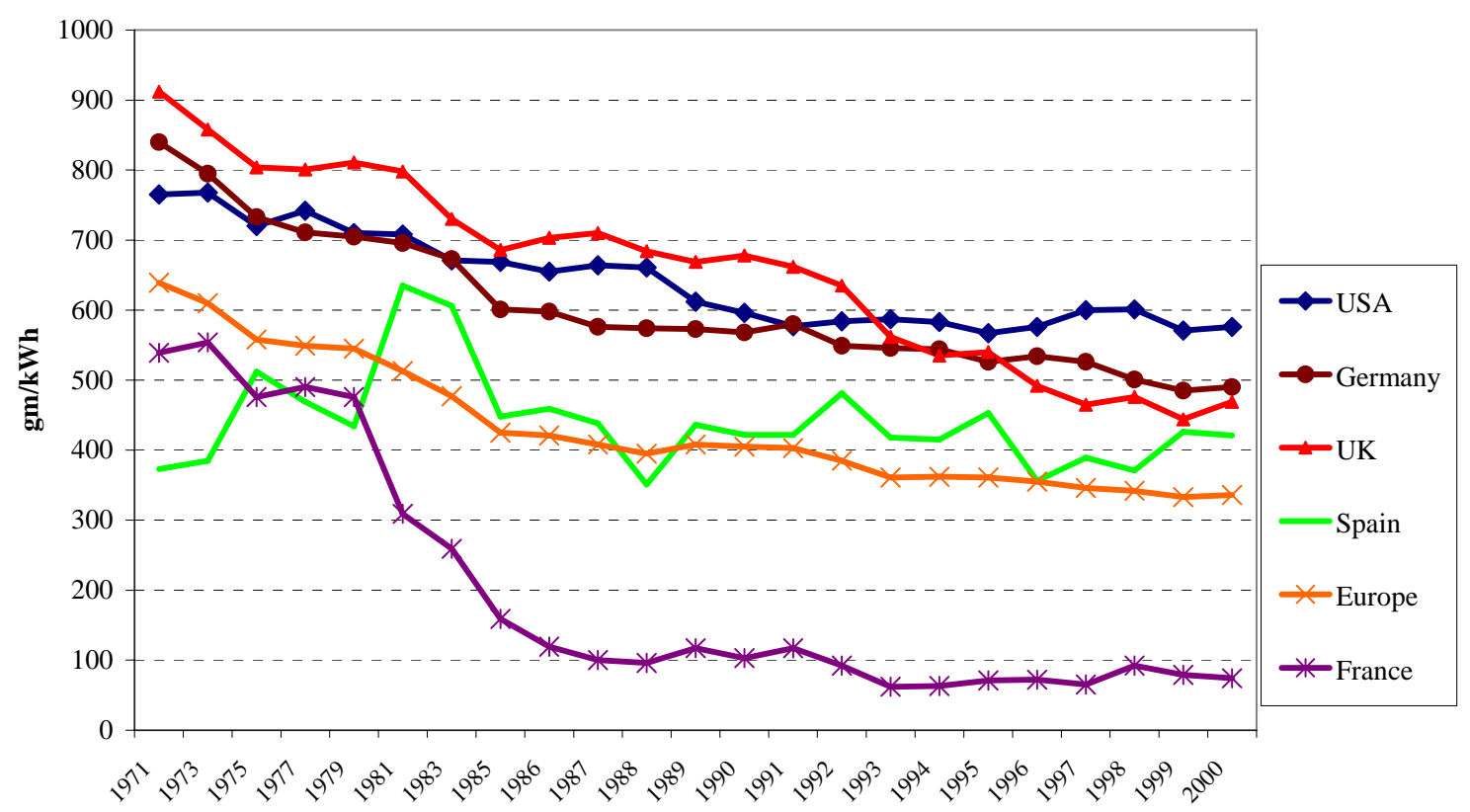

Figure 2 Electricity emissions intensity 1971-2000

Source: IEA (2002)

The UK options for delivering low-C electricity appear limited with the exception of nuclear power: hydro-electricity is limited, wave/tidal energy is too costly, biomass for electricity generation is an inefficient use compared with heat raising and requires a huge land-take, ${ }^{6}$ CCS is expensive as is solar photovoltaic, leaving onshore wind which is almost competitive at present prices but faces challenges in visual acceptability and transmission connection. Offshore wind is costly, and so the concentrated power in North Africa appears a long way off.

\section{The Case for Nuclear Power}

The government has also changed its stance since the 2002 Energy Review on the case for nuclear power. The White Paper on Nuclear Power (BERR, 2008) ${ }^{7}$ now accepts "that nuclear power is low carbon, affordable, dependable, safe and capable of increasing diversity of energy supply.” DECC (2009). Unfortunately, over the next decade instead of increasing its share of generation and helping reduce carbon intensity, British nuclear power will gradually fade away and unless new build is commissioned soon, we shall be left with just one station in the 2020s. Figure 2 makes clear what a major contribution nuclear power made to

\footnotetext{
${ }^{6}$ Running Britain's largest coal-fired station, Drax, on base load with biomass would require all the land in a disc round the station planted to biomass with a diameter of $164 \mathrm{~km}$, while wind farms to displace Drax would take up $1,750 \mathrm{~km}^{2}$, (a circle of diameter $47 \mathrm{~km}$ ) although the land beneath could still be used for agriculture. ${ }^{7}$ http://www.berr.gov.uk/files/file43006.pdf
} 
decarbonising French electricity, and had we started commissioning stations in 2002, instead of gradually putting the necessary regulatory apparatus in place from 2010, we might have been better placed to achieve impressive results by 2020, instead of observing the gradual fall in expectations between CCC (2008) and CCC (2009).

Nuclear power can deliver zero-C electricity in bulk, reliably and without intermittency, it has a very small land take in contrast to renewables, and the first set of sites and their communities are ready and willing to accept new investment. Although capital costs have risen substantially since 2005, so have those of most capital-intensive generation options, so that nuclear power still appears to be the least costly of large-scale zero-C alternatives, particularly at low discount rates. ${ }^{8}$ The main drawback is that the time to build is lengthy and uncertain, so the CCC contemplates stations only starting to arrive in 2018, followed thereafter at 18-month intervals.

Nevertheless, nuclear investment faces a number of risks:

- $\quad$ The Integrated Planning Committee may not deliver approvals in time;

- $\quad$ The waste-disposal problem may not be resolved satisfactorily;

- $\quad$ The regulatory framework for nuclear power may be taken to judicial review;

- $\quad$ The supply chain maybe insufficient to meet the UK and other demands;

- $\quad$ There may be insufficient trained personnel to construct and operate the plant;

- $\quad$ Finally, there may be problems financing the investment given the uncertainty about the future carbon price.

France demonstrated how rapidly the carbon intensity of electricity can be reduced, as figure 2 shows. Following the oil crisis of the 1970s, France embarked on a major investment programme, as figure 3 shows.

Between 1975 and 1990 France installed 50 GW of nuclear capacity at an annual rate reaching nearly 5,000 MW, comparable to the best that the United States did during this period. In contrast the UK constructed only 7 GW between 1975 and 1990. If we contrast this with the rate at which wind capacity has been built in the leading countries, Germany and Spain have added effective capacity (allowing for the relatively low load factor of 25\%) at rates less than $400 \mathrm{MW}$ effective per year, or about $10 \%$ of the rate at which France installed nuclear capacity. By 2008, Germany had the equivalent of three nuclear power stations in installed wind capacity, with Spain somewhat behind and the UK at 1 GW or just over onehalf a single nuclear power station.

\footnotetext{
${ }^{8}$ Estimates and comparisons of costs are not simple, as Roques et al (2006, 2008) show. SKM (2008) gives rather optimistic levellised costs in 2020 at £38/MWh assuming a $\mathrm{CO}_{2}$ price of $€ 30 / \mathrm{EUA}$, gas at 55p/therm and coal at \$110/tonne, when on-shore wind would be $£ 60 / \mathrm{MWh}$, offshore wind $£ 85 / \mathrm{MWh}$ and both coal and gas more expensive than nuclear power. CCC (2009, fig 4.36) shows nuclear profitable if any of the following parameters are more favourable than: cost of capital $8 \%$, construction cost $£ 2,500 / \mathrm{kW}$, capacity factor $77 \%$, EUA price lifetime (40 years) average $€ 98$ and gas at 50p/th. The source, Redpoint (2009) assumes the EUA price to rise from $€ 40$ to $€ 120$ between 2020 and 2030 and presumably further thereafter. Recent estimates for the EPR costs at Olkilouto and Flamanville are respectively $€ 3,000 / \mathrm{kW}$ and $€ 2,500 / \mathrm{kW}$ (Leveque, 2009), although these must be considered first-of-a-kind costs.
} 


\section{Average annual increment to nuclear capacity}

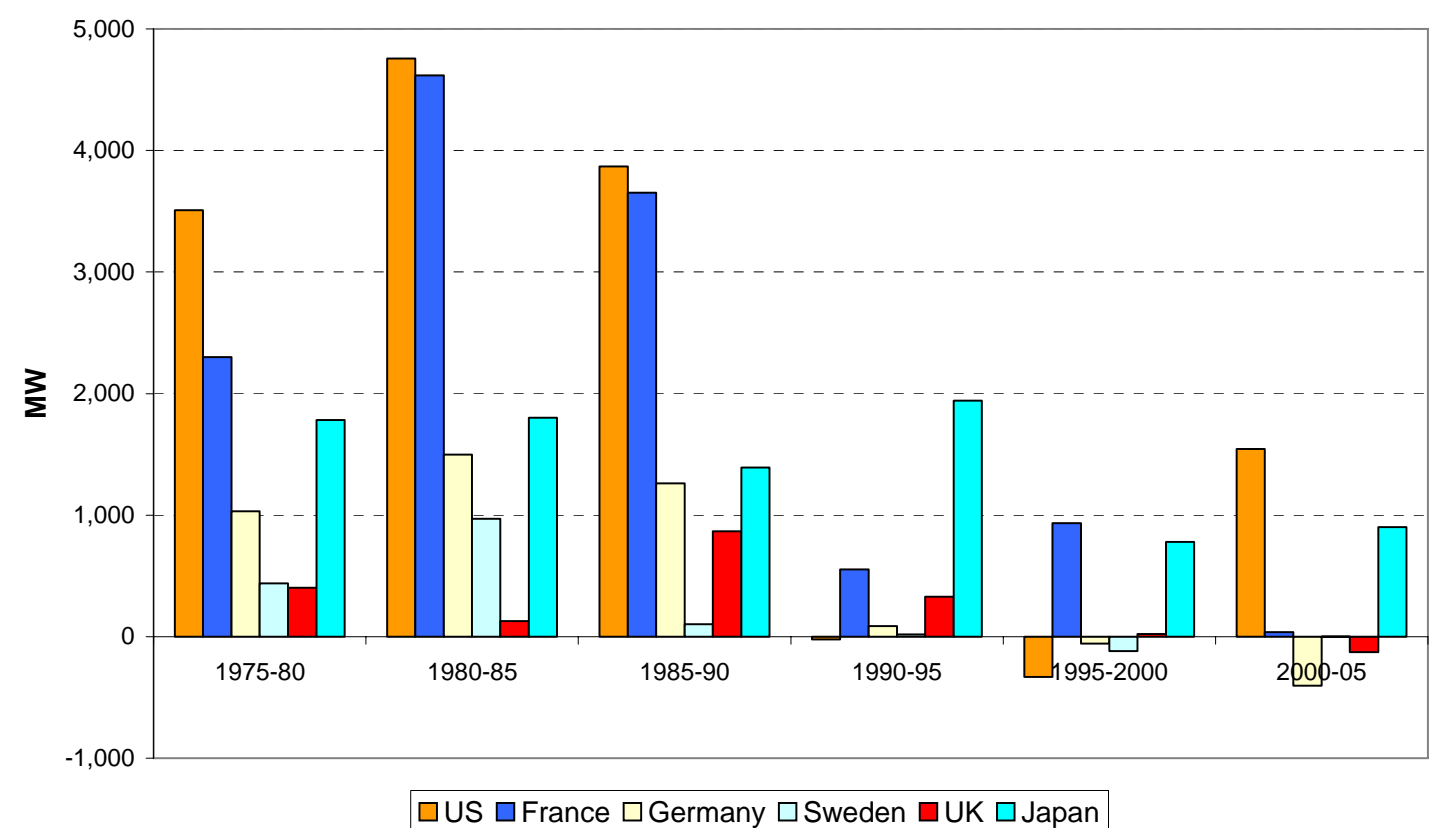

Figure 3 Average annual rate (five year averages) of nuclear build 1975-2005

Source: OECD Net Maximum Electrical Capacity, Paris OECD

\section{Nuclear power in liberalised markets}

Although clearly nuclear power can decarbonise the electricity sector over a relatively short time horizon once commissioning starts, in the past this has been undertaken by state-owned companies or regulated utilities able to recover the costs from their customers. In today's liberalised electricity markets, nuclear investments would have to be undertaken by private companies taking a commercial view about the risks involved. These are considerable. The price of electricity in the forward market moves very closely with the cost of generating using either gas or coal, allowing for the cost of $\mathrm{CO}_{2}$ required for each, as figure 4 demonstrates. Although the prices of gas, coal, $\mathrm{CO}_{2}$ and electricity are separately highly volatile, (gas prices have fluctuated between 20p/th and 110p/th and coal has fluctuated from \$50-200/ton between 2004-8) the forward clean spark spread and the forward dark green spread have remained far more stable. ${ }^{9}$ The reason is simple, the price of electricity is set by the cost of generating using the marginal fuel and the $\mathrm{CO}_{2}$ price moves to equate the marginal costs (including the EUA cost) of coal and gas. Companies with fossil generation are therefore naturally hedged against fluctuations in the input and output prices, while low-C electricity, whether renewables or nuclear, is exposed to the full volatility of the electricity price, as its variable costs are low, predictable and stable.

\footnotetext{
9 The clean spark spread is the price of electricity less the gas and EUA cost in a CCGT, while the dark green spread is the price of electricity less the coal and EUA cost in a coal-fired station. The measure the gross profit margin needed to cover the capital cost.
} 


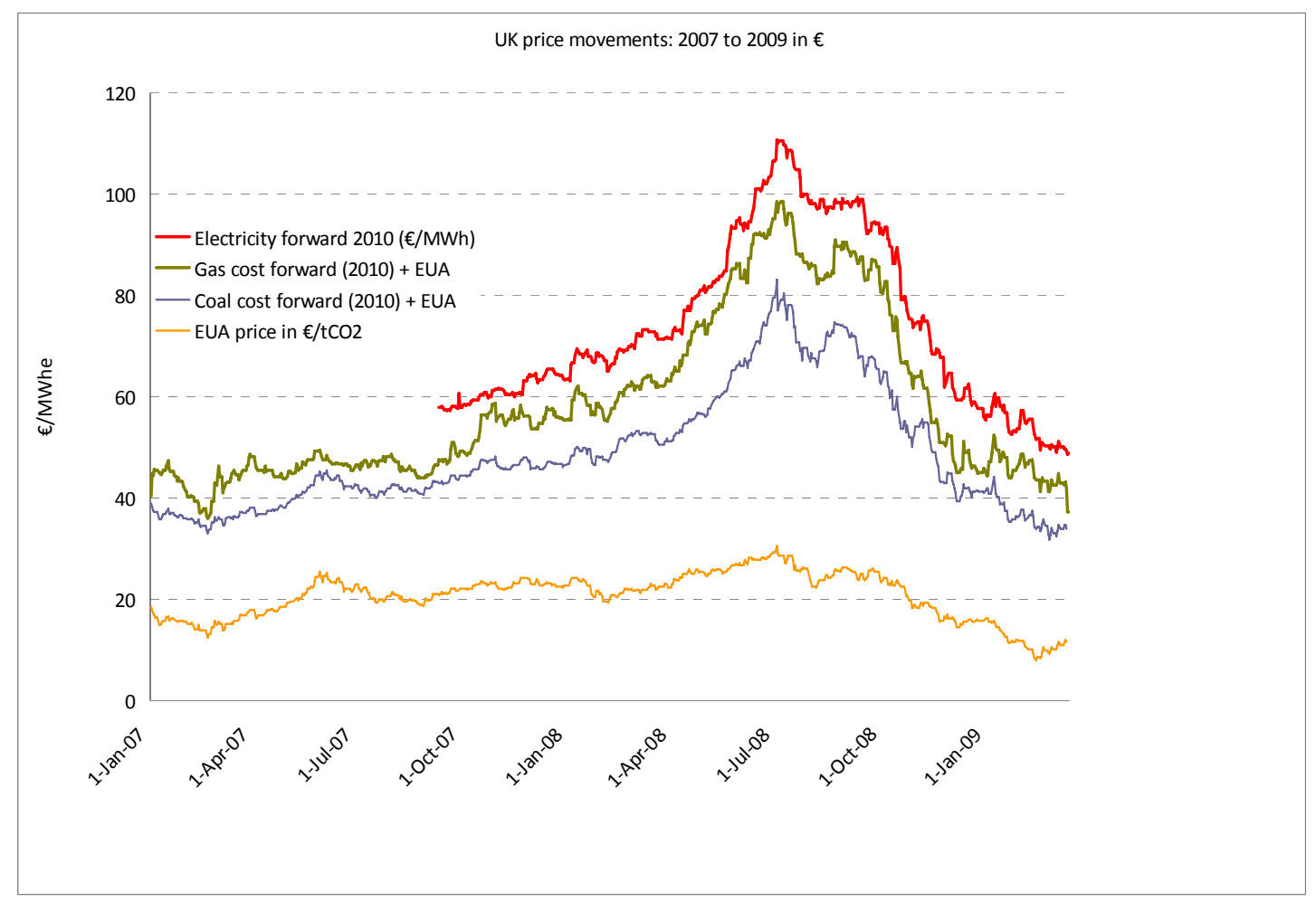

Figure 42010 Forward prices of UK electricity and the gas and coal costs, 2007-9

Source: Bloomberg data

Worse still, to the extent that the electricity sectors in the EU meet their carbon and RES targets, the demand for EUAs and even fossil fuels might fall to the extent that their prices and hence the marginal cost of electricity fell to levels that would be uneconomic. The steeper the marginal abatement curve, and the greater the uncertainty about the amount of targeted and/or supported other low-C electricity (RES, CCS), the greater the uncertainty in the future EUA price. We currently face a future in which gas-fired generators fear high gas and carbon prices but low load factors if wind is moderately successful, and low-C investors fear the opposite, favouring portfolio generation companies but disadvantaging those with specialised skills in low-C investment.

Consumers would prefer stable electricity prices, and should therefore be willing to sign contracts with those who can deliver such stable prices. The new Finnish nuclear plant Olkiluoto 3 has long-term off-take contracts with major electricity consumers, who benefit from this stability, but British domestic consumers are unlikely to want to sign long-term power contracts with electricity companies. One natural alternative is for nuclear power companies to issue bonds each paying the domestic price of $1 \mathrm{kWh}$ of electricity each year. ${ }^{10}$ That would enable a consumer to hedge the risk of fluctuating electricity bills by holding these bonds, and at current real long-term bond interest rates, even allowing for company bond risk, the cost of financing nuclear power stations would appear to be modest. Provided

${ }^{10}$ One way of determining the dividend would be to index it to the annual cost of 3,300 $\mathrm{kWh}$ for domestic customers averaged over the country, but correcting for any non-carbon taxes (such as VAT, the current CCL, and other impositions such as energy efficiency levies), using the methodology published in DECC Quarterly Energy Prices. 
the equipment suppliers and constructors could guarantee costs, merchant nuclear power investment financed in this way would appear economically attractive.

\section{Consequence of the 2020 Renewables Target}

SKM (2008) estimated in its mid scenario that to meet the UK's renewable energy target, $40 \%$ of total electricity, or 150 TWh, would need to come from renewable sources. This would require $38 \mathrm{GW}$ from wind, giving a total installed capacity of $110 \mathrm{GW}$ with the $56 \mathrm{GW}$ of conventional generation running at only a 31\% load factor to meet a peak demand of some $65 \mathrm{GW}$. The investment cost of the RES would be $£ 60$ billion with an additional $£ 10$ billion for grid expansion compared, with $£ 12$ billion spent on non-renewables, of which just under $£ 4$ billion would be nuclear power. The implied cost per tonne of $\mathrm{CO}_{2}$ saved would be $€ 95 /$ tonne to be contrasted with the present EUA price of less than €15/tonne and CCC’s more optimistic 2008 forecast of €50/EUA. CCC (2009) has scaled these figures down to 27 GW of wind and 7 GW of other RES by 2022, delivering 106 TWh (35\% of the total).

Is the implied rate of building wind power plausible, and if so, what impact might it have on market prices and risks facing nuclear investment? The CCC target of $23 \mathrm{GW}$ new wind capacity by 2020 requires an average of $2 \mathrm{GW}$ per year, which Germany has comfortably exceeded since 2002 and Spain since 2007, as figure 5 shows.

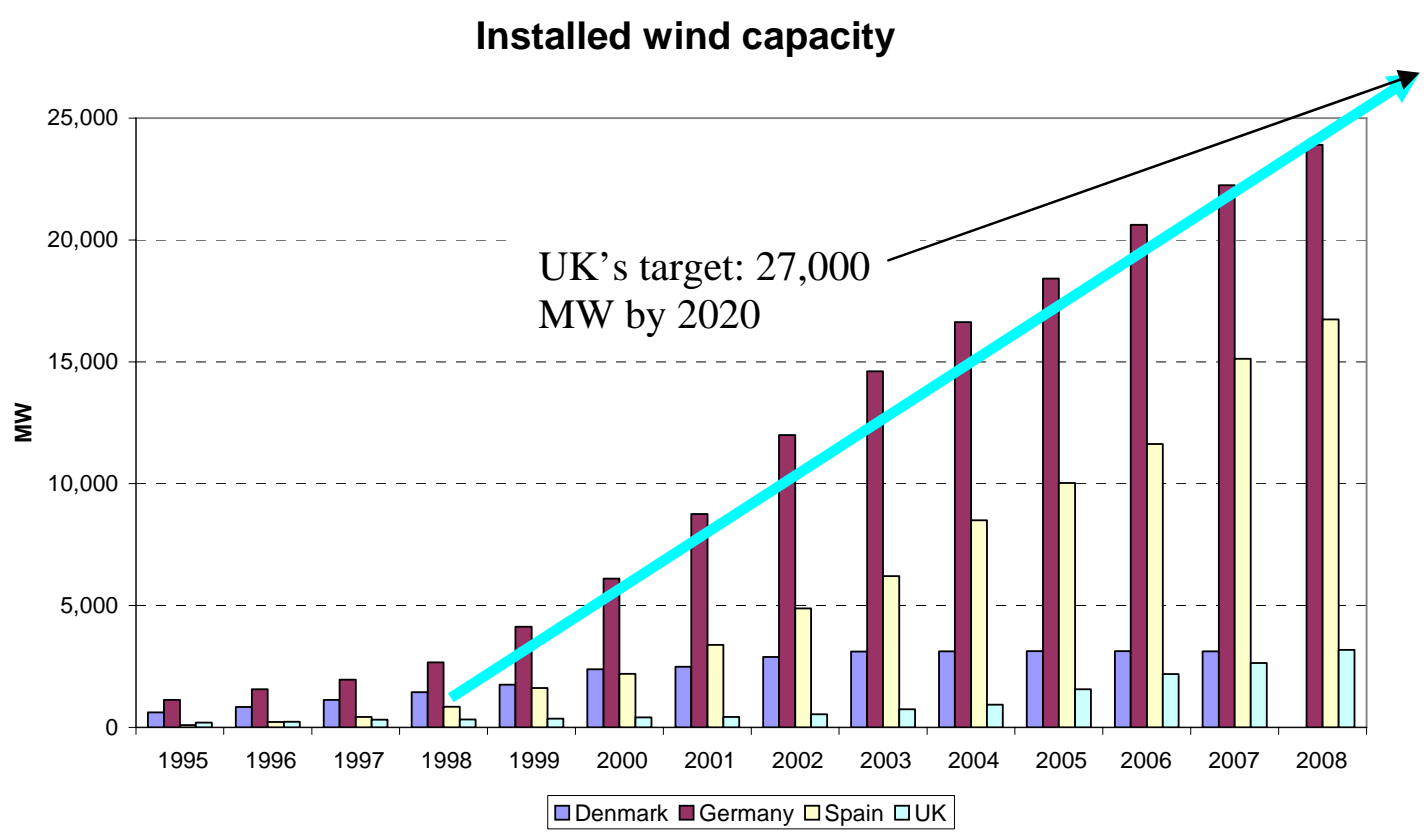

Figure 5 Installed wind nameplate capacity 1995-2008

Source: OECD Net Maximum Electrical Capacity, Paris OECD; BWEA

Clearly, if planning constraints can be overcome and the transmission delivered, the planned objectives are feasible, at least if built onshore. The implications of this amount of wind generation ought to be much greater price volatility with apparently a significant number of hours with a zero or even negative spot price as wind is spilled. This would require a corresponding number of hours of very high prices to deliver the necessary production weighted average price to cover the full costs of new investment required. 
CCC (2009) is more optimistic than earlier simulations, suggesting that even by 2030 wind power would exceed total demand less than $2 \%$ of the time, and by 2020 substantially less than one tenth of $1 \%$ of the time. Pöyry (2009) simulated the output duration curve for 40 GW of wind in Britain and found considerable annual variations (13\%) and the impact on residual demand of subtracting wind output from the (partially correlated) demand duration curve, giving the amount to be supplied by other stations, and showing some $5 \%$ of hours of excess supply (but this is very non-linear in the wind capacity, explaining the low spill fraction under the CCC's 2020 target of 27 GW wind).

Denmark, with some 25\% wind but the option of exporting surplus power, already has negative prices for many hours per year, to the point that owners of CHP plant now find it periodically profitable to replace gas in heat raising and power generation with using electricity to provide the hot water without generating any power. Building more interconnectors to the Continent and especially Norway, with its storage hydro, may become very attractive and mitigate some of the excess supply zero-price periods.

Perhaps the more serious issue is that intermittent generation requires considerably larger reserves. Pöyry (2009) found that there were 209 hours in the period 2000-7 with zero wind output, although only one period of 3 days of zero wind. In such periods either demand would need to be scaled back, perhaps dramatically, or considerable conventional reserve capacity would be needed that must be paid to remain on the system. Pöyry estimated reserve requirements of 9 GW in 2020 and over 10 GW in 2030. The problem is made worse by increasing fractions of nuclear power, which it is considerably more expensive to operate in flexible mode (Pouret et al, 2009).

Paying for reserves could be either through capacity payments, contracts, or periodic very high price spikes. Capacity payments under the former electricity Pool were paid on the value of lost load (£2,000/MWh in 1990) times the loss of load probability, but this was both unpredictable and very volatile. A cheaper alternative might be for the System Operator (SO) to contract sufficiently far ahead to secure such reserves at a reasonable cost, but this would require changing the incentives on the $\mathrm{SO}$ and changing the regulatory system of rewarding these functions. Failing that, the necessary volatility in the spot price might induce suppliers to contract for availability in capacity without additional encouragement, but this risks the necessary contracts not being in place until too late to secure the required reserves. Certainly Ofgem in its Project Discovery (Ofgem, 2009a) is concerned that the proportion of plant that is flexible will fall from nearly $60 \mathrm{GW}$ in 2009 to about $40 \mathrm{GW}$ in 2020, at a time when flexible plant will be even more necessary.

Even if this problem is adequately addressed, there remains the question whether transmission investment will be adequate, timely, and efficiently used. Ofgem (2009a) argues that there is a strong case for building offshore links along the west coast of Britain and reinforcing north/south links between Scotland and England, presumably because of the difficulty of securing planning consent to build more cheaply on-shore, and strengthening the grid in East Anglia and Wales. They propose further offshore cables from northeast Scotland to the north east of England at a later date and under some scenarios these could be used to interconnect with offshore wind farms and the Continent - again costly solutions. 
The current GB transmission access arrangements appear quite unsuitable for massive wind generation. At present generators seeking connection must wait until reinforcements are in place to allow firm (i.e. base load) access to the grid - "invest then connect". Such reinforcements would be excessive for wind capacity with an availability of less than $30 \%$, as demand will not increase much but capacity is expected to increase by nearly $50 \%$. The present arrangements would impose excessive delays in connecting wind farms, and provide excessive capacity. An interim solution of "connect and manage" would require the Transmission System Operator (TSO) to use contracts and the balancing mechanism to manage congestion while recovering the costs from consumers. This would provide weak incentives to generators to manage their output unless the TSO were incentivised to offer appropriate contracts, and would surely be a costly solution for dealing with Scottish congestion. Constraint costs arising from "Scottish Actions" (i.e. dealing with the constraints arising from exporting from Scotland) rose from $£ 42$ million in 2007/8 to $£ 231 \mathrm{~m}$ in 2008/9 and are forecast by NGET to rise to $£ 290 \mathrm{~m}$ in 2010/11 (Ofgem, 2009b). There is previous experience of the cost of poor incentives to manage congestion costs - in the four years after privatisation total constraint costs in England and Wales doubled to $£ 509 \mathrm{~m}$ per year, before eventually falling to $£ 37 \mathrm{~m}$ in $1997 / 8$ and then to $£ 12 \mathrm{~m} /$ year in 2001/2 - in 2008/9 the constraints in England and Wales were still only £30 m so Scotland is now driving the GB total costs. Frontier Economics (2009) estimates that "connect and manage” could increase congestion costs by between $£ 1.9$ bn and $£ 3.5$ bn in net present costs up to 2020 compared with the old system of "invest then connect".

Nor are current balancing arrangements satisfactory as the day-ahead market is ill suited for contracting intermittent wind generation, particularly as wind forecasts become increasingly accurate down to about 4 hours before despatch. At present the dual price system is narrow, illiquid, very volatile, and penalises those who have not fully contracted their output well-before gate-closure (1 hour before dispatch). ${ }^{11}$ Balancing costs are also high compared to recent constraint costs - estimated to be $£ 366 \mathrm{~m}$ for 2009/10 but rising to $£ 525$ $\mathrm{m}$ for 2011/12, and that is before there is substantial new wind generation (Ofgem, 2009b). Timely wind forecasts should allow more efficient despatch of fossil generation, allowing more time for ramping and cold-starts, but this would be more economically achieved with central despatch rather than the present system of self-despatch.

\section{The Argument for Change}

If the present system of access and balancing is flawed and inefficient, then an economist would argue that it ought to be possible to make everyone better off by improving the system. The challenge is to identify the efficient long-run solution that can co-exist with an evolving regime for incumbent generators, and then only offer that new regime to all new connections. To avoid litigation it should compensate incumbents for any change while encouraging them to migrate to the new access regime. The efficient long-run solution is nodal pricing (or locational marginal pricing) with central despatch where nodal pricing reflects both

${ }^{11}$ Newbery $(2005,2009)$ 
congestion and marginal losses at each grid connection point (Brunekreeft et al 2005) . It has the advantage that it reduces prices in export-constrained zones and thus encourages efficient investment location for generation and also providing price signals for expanding the grid. Central despatch enables both efficient scheduling and balancing as a single coordinated activity. Until recently, such a system would have been criticised as an academic utopian exercise, but first New Zealand and then $\mathrm{PJM}^{12}$ in the US have demonstrated that it can work, in the latter case on a system several times as large as the UK. The lesson has been learned, and New York, New England, California and Texas have either introduced the system or are planning to do so shortly.

The obvious objections to nodal pricing are that it would appear to disadvantage Scottish generators (although by lowering Scottish wholesale prices it would benefit Scottish consumers) and would produce large shifts in revenue between Scottish and more southerly generators for relatively small efficiency gains. These objections have been successful in previous UK litigation and suggest strongly the importance of compensating any losers before such a change is made. It is worth remembering that the transition from the CEGB to a liberalised market was carefully designed with contracts to manage the transition so that large industrial consumers, coal miners, and the generating companies were insulated against any unforeseen price changes or price volatility in the wholesale market. That lesson appears to have been lost, and Ofgem has been reluctant to propose contractual transition solutions to overcome the inefficiencies in the transmission access regime.

Again, the US provides evidence that such contracts can be designed. Existing generators would receive long-term transmission contracts that had a strike price equal to their current Transmission Entry Capacity (TEC) charges, but would allow them to sell additional power at the locational marginal price (LMP) or to receive the difference between the contract price and the LMP if they sold less. This would leave generators significantly better off than at present and would appear to leave no transmission rights for intermittent generation other than those secured in the stock market. The challenge would therefore be to devise contracts that reduced these excess incumbent rents, ensuring that they were still attractive, while facilitating the entry of wind as it were built. Fortunately, the TEC charges can be revised annually subject to the regulated total revenue for the TSO, National Grid, and it should be possible therefore to devise an evolution of these charges that would encourage incumbents to reduce the TEC they claimed, releasing capacity for wind, and with careful design reducing the excess rents.

\section{Financing Low-Carbon Electricity}

Delivering low-C electricity at least cost will require an adequate, credible and durable $\mathrm{CO}_{2}$ price for mature technologies, and a minimally distorting form of support for potential future low-C technologies. Neither of these is assured at present. CCC (2009) recommended that the climate change levy should be exempted for all low-C generation (not just renewables and "good" CHP) if it is to be a genuine climate change levy and not an electricity tax. The $\mathrm{CO}_{2}$

\footnotetext{
${ }^{12}$ The Pennsylvania-New Jersey Maryland interconnection, although now much wider than its original geographic area.
} 
price needs to be supported at an adequate level, which should increase steadily over time as we approach the date at which the costs of climate change become more appreciable. Investment uncertainty would be reduced by feed-in tariffs (FITs) for new low-C generation, phasing out the existing Renewable Obligation Certificate (ROC) support system. ${ }^{13}$

The difficulty with FITs is the risk that the tariff will be either set too high, producing excess rents and high consumer prices, or too low, risking undersupply. For mature technologies such as wind it should be possible to calculate acceptable FITs and the German experience suggests that this is correct. For less mature technologies like PV, the evidence is that FITs have been set too high in Spain, Germany and the UK, leading to excess demand, inflated prices, exhausting the funds prematurely and leading to a collapse in the nascent PV supply industry. That suggests using tender auctions in which bidders would offer combinations of a subsidy per kW capacity when available and per kWh generated, with penalties to ensure credible bids, allowing the auction office to select the least-cost options. ${ }^{14}$ The alternative of placing low-C obligations on suppliers might lead to innovative mechanisms, but runs into the problem that consumers can switch suppliers at short notice, raising risk and hence cost.

All of these mechanisms for supporting low-C electricity tend to bypass the market, except for the discredited ROC scheme. There is a danger that if a large fraction of generation is intermittent, or inflexible (like nuclear), ${ }^{15}$ or operating with long-term contracts to deliver adequate reserves, the market will fail to deliver its intended advantages.

\section{Reforming the market design}

If, as many believe, the present market design is not well suited to massive renewables, then it is worth setting out the criteria that any reformed market should meet. Liberalised markets have been justified for producing more efficient outcomes than regulated markets, for which they need to encourage competition, and that means potential entry. The major gains are to be had from improved investment delivery, so the market should provide incentives for timely, efficient (by location and technology) and adequate investment in generation and transmission, reflecting the comparative advantage that each country and location has in delivering appropriate low-C generation. Clearly, the market needs to reflect the social cost of carbon, support RD\&D without distortions, ensure that the existing plant is efficiently despatched and that the final price is affordable to consumers. Given that the carbon price is

\footnotetext{
${ }^{13}$ See Mitchell and Connor (2005) for a cogent critique of UK support for renewable energy.

14 The Non-fossil fuel obligation (NFFO), put in place by the Electricity Act 1989 and continued until replaced by the Renewables Obligation, collected funds from a levy or tax on fossil-generated electricity. Originally primarily designed to raise funds for covering nuclear fuel liabilities, some part of the revenue was used to run tender auctions for renewables, with an impressive fall in the FIT prices paid in successive rounds (see http://www.nfpa.co.uk/index.html). Only a modest fraction of wind projects that were accepted were actually built, suggesting that the costs of tendering were too low to develop credible projects - and hence some commitment to delivery might be desirable, although more research is clearly needed to improve the procurement of RES.

${ }^{15}$ Whether nuclear power is flexible or not depends on its type and economics - see Pouret et al (2009). E.On’s operational experience suggests PWRs can be capable of responding to wind variations (Micklinghoff, 2007).
} 
both too low and too unpredictable, and that the UK's RES support through ROCs is costly and inefficient, the country faces essentially two alternatives.

One is to abandon the liberalised market and move to a single buyer model in which the single buyer, probably the TSO, contracts for the portfolio of low-C generation by location to minimise the total cost of transmission and generation. This would restore some of the synergies of the old pre-liberalised CEGB, but might, if tendering for contracts were competitive, avoid the inefficiencies. It could overcome the risks and costs facing nuclear power where the electricity price is both too volatile and possibly thought to be too low because of uncertainties about the $\mathrm{CO}_{2}$ price, providing the single buyer were mandated to achieve the carbon and RES targets and allowed to charge consumers accordingly. The obvious problem is that the single buyer would be a monopoly and in need of regulation, which would be challenging as it would combine elements of natural monopoly - where to locate transmission and generation, and markets - how to balance the different dimensions of the bids in the tender auctions.

The alternative is to reform the market to meet some of the drawbacks of the current design. As argued above, this would involve a shift to nodal pricing with central despatch and the SO given a longer time horizon (4 plus years) to contract for balancing and reserve services. ROCs for future RES. would be replaced by a FIT paying a capacity payment for availability and an energy payment if despatched, related to the variable costs, which for wind would primarily be the extra short-run balancing costs. That should avoid wind bidding negative prices and disrupting the spot market and should provide greater investment assurance for new RES.

SKM (2008) estimated that the cost of supporting renewables could be between $£ 60$ 90 per household or $£ 5.2-7.8$ billion per year. Instead of passing the extra costs of supporting RES through to final consumers, the RD\&D element could be financed from a carbon tax and/or charging the full rate of VAT on energy. Raising the rate of VAT from $5 \%$ to $17.5 \%$ would raise about $£ 3$ billion extra per year, while raising the $\mathrm{CO}_{2}$ price from $£ 10 /$ EUA to $£ 25 /$ EUA by a $\mathrm{CO}_{2}$ tax of $£ 15 /$ tonne for electricity would raise $£ 2.75$ billion per year at current electricity emissions intensity, and taxing final gas consumption would raise a further $£ 1.5$ billion; altogether $£ 7.3$ billion per year or close to the likely extra cost. Of course as the carbon intensity of electricity fell that element of revenue would decrease, but over time the carbon price should rise, and depending on the shortfall between the EUA price and social cost of carbon, revenue might rise or fall from this estimated amount.

The argument for transferring RD\&D support from electricity to general taxation is simple - taxes on single products are more distorting than taxes on a wider tax base, and removing an artificial distortion (the reduced VAT rate on energy amounts to an energy subsidy to final consumption) reduces the dead weight cost of taxation. RD\&D is a public good benefiting ultimately the planet and indirectly future UK residents, and should not therefore be charged to current consumers, particularly as electricity is a price and income inelastic service and therefore would fall more heavily on the poor (which is the justification for the lower VAT, although not a sound one). 


\section{Conclusions}

Nuclear power offers one of the most credible large-scale sources of zero-C electricity, although given past Government delays there will now be a lengthy period before the nuclear supply industry can ramp up to deliver the required rates of investment previously seen in the 1980s. Even if that can be achieved, the present liberalised market is poorly designed to encourage nuclear and other low- $C$ investment without an adequate carbon price. The situation is likely to be made more difficult if Britain is to reach its RES 2020 target, as this will require substantial wind, which will cause considerable volatility in market prices and significant periods of very low prices under the present market design, not to mention a lowering of the EUA and possibly gas prices. That further justifies a major reform of the electricity market design or its replacement by a single buyer model and better underwriting of the carbon price.

Current renewable support can be justified by the learning benefits to the extent that the technology could become commercially viable in other countries. The present 2020 targets for the EU have the benefits of sharing the burden of providing the public good of $\mathrm{RD} \& \mathrm{D}$, but fail to insure that each country invests in the technology with the best long-term prospects suited to the country's resources, rather than choosing the current least-cost option. Transmission access arrangements will need significant modification to handle massive renewable generation, and will need careful transition arrangements to prevent litigation in a privately owned generation market. Current support in the UK for RES is both risky and costly and requires a shift to long-term contracting, which threatens the liberalised market unless we move back to something like the pool with nodal pricing.

Supporting the carbon price should ideally be done at the EU level, and as between the alternatives for the UK of offering contracts for differences on the carbon price or imposing an additional carbon tax on fossil generation, the latter is fiscally preferable to the former and although it would raise the cost of electricity to electricity-intensive industries, it would not cause any relocation of generation abroad. It might be necessary to provide countervailing subsidies to electricity-intensive industries to prevent them moving off-shore, or exemptions from the carbon tax, as was done in Scandinavia when the carbon tax was introduced there, but this would need careful design to avoid excessive subsidy or comparatively disadvantageous industries and to avoid conflicts with EU legislation. Provided the future carbon price is underwritten at a sufficiently high level, nuclear power would seem viable in a liberalised market without long term off-take contracts, particularly if nuclear generating companies issued electricity-indexed bonds to consumers to reduce the cost of capital. 


\section{References}

BERR (2008) Meeting the energy challenge: a White Paper on nuclear power, January, available at http://www.berr.gov.uk/files/file43006.pdf

Brunekreeft, G., Neuhoff, K. and Newbery, D. (2005) 'Electricity transmission: an overview of the current debate’, Utilities Policy, 13 (2), June, 73-94.

Committee on Climate Change (2008) Building a low-carbon economy - the UK's contribution to tackling climate change 1st December 2008 available at http://www.thecc.org.uk/reports/building-a-lowcarbon-economy

Committee on Climate Change (2009) Meeting Carbon Budgets - the need for a step change, 12 October 2009 at http://www.theccc.org.uk/reports/progress-reports

DECC (2009) The UK Low Carbon Transition Plan, available at http://www.decc.gov.uk/en/content/cms/publications/lc_trans_plan/lc_trans_plan.aspx

Frontier Economics (2009) An assessment of the potential impact on consumers of connect and manage access proposals, a report prepared for Ofgem, November, at http://www.ofgem.gov.uk/Networks/Trans/ElecTransPolicy/tar/Documents1/Frontier_CM_Constraints. pdf

IEA (2002) $\mathrm{CO}_{2}$ Emissions from Fuel Combustion, Paris, IEA.

Leveque, F (2009) Nuclear generation costs - revisiting estimates (once again) at http://www.energypolicyblog.com/2009/10/23/nuclear-generation-costs-\%E2\%80\%93-revisitingestimates-once-again/

MacKay, D (2009) Sustainable energy - without the hot air, available at http://www.withouthotair.com/

Micklinghoff, M. (2007) 'Confronting economic regulation and safety regulation’ paper to the Berlin CeSSA conference, May, at http://www.cessa.eu.com/sd_papers/berlin/CeSSA_Berlin_207_Micklinghoff.pdf

Mitchell, C. and P. Connor (2004). 'Renewable energy policy in the UK 1990-2003', Energy Policy 32(17): $1935-1947$

Newbery, D.M. (2005) "Electricity liberalisation in Britain: the quest for a satisfactory wholesale market design”, Energy Journal, Special Issue on European Electricity Liberalisation, ed. D Newbery, 43-70

Newbery, D.M. (2009) 'Market design for a large share of wind power', Energy Policy at http://dx.doi.org/10.1016/j.enpol.2009.07.037

Ofgem (2009a) Project Discovery, available at http://www.ofgem.gov.uk/MARKETS/WHLMKTS/DISCOVERY/Documents1/Discovery_Scenarios ConDoc_FINAL.pdf

Ofgem (2009b) ‘Ofgem’s initial comments on national Grid System Operator Incentives from April 2010’ letter dated 30 Nov available at http://www.ofgem.gov.uk/Markets/WhlMkts/EffSystemOps/SystOpIncent/Documents1/Ofgem\%20init ial\%20comments\%20on\%20National\%20Grid\%20System\%20Operator\%20Incentives.pdf

PIU (2002) The Energy Review, Cabinet Office Performance and Innovation Unit, at http://www.cabinetoffice.gov.uk/media/cabinetoffice/strategy/assets/theenergyreview.pdf

Poulet, L., N Buttery and W. Nuttall (2009) 'Is nuclear power inflexible?’, Nuclear Future, 5 (6) p333-44

Pöyry (2009) Impact of Intermittency Summary Report available at http://www.poyry.com/linked/group/study

Redpoint (2009) Decarbonising the GB power sector, available at http://hmccc.s3.amazonaws.com/docs/FINAL\%20Decarbonising\%20the\%20GB\%20power\%20sector_ v1.pdf

Roques, F.A., D. M. Newbery and W. J. Nuttall (2008) 'Fuel mix diversification incentives in liberalized electricity markets: a Mean-Variance Portfolio Theory Approach’ Energy Economics Vol 30/4 pp 1831-1849

Roques, F. A., W. J. Nuttall, D. M. Newbery, R. de Neufville, S. Connors (2006) "Nuclear Power: a Hedge against Uncertain Gas and Carbon Prices?” The Energy Journal, 27, (4) 1-24

SKM (2008) Growth Scenarios for UK Renewables Generation and Implications For Future Developments and Operation of Electricity Networks BERR Publication URN 08/1021 available at http://www.berr.gov.uk/files/file46772.pdf 